\title{
Tobacco free workplace policies and low socioeconomic status female bartenders in San Francisco
}

\author{
Roland S Moore, Juliet P Lee, Tamar M J Antin, Scott E Martin
}

J Epidemiol Community Health 2006;60(Suppl II):ii51-ii56. doi: 10.1136/jech.2005.045591

\begin{abstract}
See end of article for authors' affiliations

.....................

Correspondence to: Dr R S Moore, Prevention Research Center, Pacific Institute for Research and Evaluation, 1995

University Avenue, Suite 450, Berkeley, CA 94704 USA; roland@prev.org
\end{abstract}

Accepted for publication 10 June 2006

\begin{abstract}
Study objective: Multiple studies have found that, compared with employees in other settings, workers in bars and restaurants have been exposed to high levels of secondhand smoke, putting them at increased risk for health complications. Among these bar employees are many women of low socioeconomic status (SES). Smoke free workplace ordinances have been extended to bars and restaurants in cities and states throughout the USA; some bars, however, continue to be out of compliance with these laws. The objective of this study is to assess the relation between bartender gender and smoke free workplace compliance in bars.

Design: This paper reports on analyses of observational data on compliance with smoke free workplace policy in 121 randomly selected bars together with qualitative data from semi-structured interviews with bartenders and patrons in bars.

Setting: San Francisco County bars.

Main results: Findings from this research showed that smoke free policy non-compliance was associated with bars in which women were bartenders, increasing their tobacco exposure compared with male bartenders. In interviews, although some female bartenders expressed ambivalence toward the smoke free ordinance, many others described experiencing positive health and social consequences when the bars in which they worked could eliminate interior smoking.

Conclusions: The analyses presented here shed light on the benefits of improving the workplace environment for low SES female bartenders through the extension of strong smoke free workplace policies to all workplaces, including bars.
\end{abstract}

$\mathrm{T}$ he bar and restaurant industry provides accessible employment opportunities for women, particularly those who might lack the necessary educational, technical, or language skills needed for other professions. Since Victorian times, women have played a leading part as bartenders. ${ }^{1}$ More recently, in California, many immigrant women fall in this category. Although this part of the service industry may be comparatively easy to enter, it presents few opportunities for professional or financial growth. Among these bar employees are many women of low socioeconomic status (SES). According to US census data from 2000, more than half of people reporting their employment as bartending were women (see table 1). Of these women, over a third, or $35.8 \%$, worked full time at this job. In 2000, the median annual salary reported for full time female bartenders in the USA at \$16 149 was slightly above the federal poverty level for a family of three (\$14 150). In California, with costs of living much higher than most other parts of the country, income levels for full time female bartenders centred around \$17 527. Although real incomes for these workers may have been somewhat higher than those reported (bartenders, like waitresses, are required to include tips as income, but may underreport), still only $9.9 \%$ of female bartenders in California possessed a college degree. This lack of higher education makes professional and financial advancement in other professions more difficult.

In the context of the rapidly growing global movement to relieve workers from exposure to environmental tobacco smoke (ETS), bars and restaurants have functioned, until recently, as the last stronghold of workplaces where smoking is permitted. ${ }^{3}$ California has been at the forefront of tobacco control efforts since the late 1980s, attempting to change social norms about tobacco use and availability through policy implementation and education. ${ }^{56}$ In 1998, implementation of the
California Smoke-Free Workplace Law (California Assembly Bill or $\mathrm{AB}$ 13) was extended to bars and restaurants despite concerns voiced by the tobacco industry about potential impacts on bar revenues and infringement on citizens' rights to smoke. ${ }^{7}$ Recent studies, however, have outlined the health benefits of smoke free workplace policies for bar employees. ${ }^{8}$ Multiple studies have found that workers in bars and restaurants suffer from increased exposure to secondhand smoke when compared with employees in other settings. ${ }^{9-15}$

How might varying degrees of compliance with smoke free policies be associated with socioeconomic and demographic differences in ETS exposure among workers? ${ }^{13}$ This paper discusses two consecutive projects at the Prevention Research Center that have been investigating the effects of the smokefree workplace legislation, California $\mathrm{AB}$ 13, in bars in major urban areas of the state. In the first of these studies (study 1), observations and interviews were conducted in 121 randomly selected San Francisco stand-alone bars-those not attached to hotels or restaurants. A key finding in this first study was that observed smoking inside bars-in defiance of the lawwas significantly related to the presence of female bartenders. Additionally, in contrast with most other kinds of standalone bars, nearly all the sample bars serving primarily Asian and Irish clientele were out of compliance with $\mathrm{AB}$ 13, whereas those serving predominantly Latino patrons were highly compliant with the smoke free workplace policy. The second study (study 2), still underway, has followed up on these findings by collecting data in all bars serving primarily Irish, Asian, and Latino patrons in San Francisco County. Interviewing female bartenders has been a focus of this study. Through consideration of observation results and

Abbreviations: SES, socioeconomic status; ETS, environmental tobacco smoke; HLM, hierarchical linear modelling 
Table 1 Income, education, and sex among US bartenders

\begin{tabular}{|c|c|c|c|c|c|c|}
\hline & & Worked in 1999 & Median earnings & $\begin{array}{l}\text { Percentage college } \\
\text { graduates }\end{array}$ & $\begin{array}{l}\text { Percentage year } \\
\text { round full time } \\
\text { workers }\end{array}$ & $\begin{array}{l}\text { Median earnings for full time } \\
\text { year round }\end{array}$ \\
\hline \multirow[t]{3}{*}{ USA } & Both sexes & 356955 & $\$ 12612$ & 11.3 & 40.6 & $\$ 18844$ \\
\hline & Men & 162200 & $\$ 16040$ & 15.3 & 46.5 & $\$ 21428$ \\
\hline & Women & 194755 & $\$ 11257$ & 8 & 35.8 & $\$ 16149$ \\
\hline \multirow[t]{3}{*}{ California } & Both sexes & 34375 & $\$ 15150$ & 13.6 & 34.8 & $\$ 21326$ \\
\hline & Men & 19530 & $\$ 17825$ & 16.5 & 39.8 & $\$ 23186$ \\
\hline & Women & 14845 & $\$ 11734$ & 9.9 & 28.1 & $\$ 17527$ \\
\hline
\end{tabular}

Source: US census $2000^{2}$

interviews with female staff in San Francisco bars serving Asian, Irish, and Latino patrons, this paper's discussion explores these differences in rates of smoke free policy compliance and illustrates how, in practice, smoking in bars disparately affects low SES female bartenders working in this industry.

\section{METHODS}

\section{Observations and interviews}

In this paper we present findings from the two bar smoking projects. Study 1 focused on understanding differing rates of non-compliance among a random sample of San Francisco stand-alone bars. Study 2 has concentrated on San Francisco stand-alone bars serving primarily Irish, Asian, and Latino patrons. Both studies have used a mixed method approach to research, coupling quantitative and qualitative data generated though structured observation with data collected from semi-structured interviews with bar patrons and staff. All procedures in both studies were reviewed for compliance with research ethics guidelines and were approved by the institutional review board of the Pacific Institute for Research and Evaluation. After identifying the potential universe of urban stand-alone bars through compilation of California Alcohol Beverage Control data, listings in local print and internet bar guides, phone books, and newspapers targeting various ethnic groups, a rigorous in-person survey was conducted in each study to verify the existence, names, and addresses of these businesses and to establish that the bars met the study criteria. Study 1 focused on 121 randomly selected bars in San Francisco, and study 2 collected data in 90 stand-alone bars in San Francisco, including 28 Asian patron bars, 25 Latino patron bars, and 37 Irish patron bars.

In both studies, pairs of trained research assistants conducted hour long, structured observations in all selected bar locations. The observations were conducted as participant and naturalistic observations, but with limited actual participation. The observers were instructed in ways to

Table 2 Descriptive information on the sample $(n=479$ observations)

\begin{tabular}{lll}
\hline Variables & $\%$ & SD \\
\hline $\begin{array}{l}\text { Dependent variable } \\
\text { Patron smoking non-compliance }\end{array}$ & 0.30 & 0.46 \\
Covariates & & \\
Night level & 0.24 & 0.42 \\
Ashtrays present & 0.53 & 0.50 \\
Male bartender only & 0.34 & 0.48 \\
Female bartender only & 0.10 & 0.30 \\
Female and male bartenders & 0.14 & 0.35 \\
Employee smoking & & \\
Bar level & 0.09 & 0.28 \\
Asian & 0.05 & 0.21 \\
Irish & 0.07 & 0.26 \\
Latino & & \\
\hline
\end{tabular}

purchase but not consume drinks, and to keep their interactions with other patrons and staff friendly but brief. Pairs of observers were deployed for safety as well as to minimise the "stranger effect" and to reduce the need for the observers to engage in extended conversations with other patrons. Each observer conducted a walk-through of the entire bar and was instructed to note details on setting, patrons, staff, and social interactions, as well as information on smoking in and around the bar. Immediately after the observation, each research assistant filled out a survey instrument programmed on handheld computers and jotted down descriptive field notes to aid in writing semi-structured observation narratives. All data were then transmitted electronically to the research staff. After four observations in study 1 and three observations in study 2 were completed in each of the selected locations, trained interviewers conducted semi-structured interviews with bar patrons, staff, and managers. These interviews were designed to assess the workplace culture of the sample bars and to gain a more complete understanding of the impact of the smoke free policy on these establishments.

In study 2, project interviewers have recruited and interviewed a total of 35 bar staff and patrons in San Francisco to date. These interviews include 13 female bar staff from bars serving predominantly Asian, Irish, and Latino patrons (five, four, and four bar staff, respectively). Many bartenders, especially from non-compliant bars, were reluctant to discuss legal issues with strangers, therefore necessitating an opportunistic sampling strategy in recruiting respondents. Our recruitment and use of bilingual/bicultural interviewers fluent in Spanish, Korean, and Cantonese mitigated this concern somewhat. Before scheduling an interview, bartenders were screened to make sure they were not new bar employees. All respondents were given a $\$ 40$ stipend for participating, and all interview data have been kept confidential, with respondent as well as bar identities coded.

All interviews were conducted in the informant's first language and subsequently transcribed and, if necessary, translated into English. After data collection, observation narratives and interview transcripts were integrated into ATLAS.ti, a qualitative data management software package, for thematic analysis (Scientific Software Development, Berlin, 2005). Relevant quotes from observations as well as interviews with female bartenders and managers are presented below to illustrate some of the recurring themes that emerged through content analysis. The quotes are translated into English if the interviews were conducted in Spanish, Cantonese, or Korean. Survey data recorded on handheld computers were uploaded to networked PCs, transferred to SPSS, and portions were entered into SAS for hierarchical linear modelling (HLM) analyses.

\section{Hierarchical linear modelling in study 1}

Study 1 had two units of analysis in seeking predictors of non-compliance with $\mathrm{AB}$ 13: (1) each night's hour-long 


\begin{tabular}{|c|c|c|c|c|c|c|}
\hline & \multicolumn{2}{|l|}{ Model 1} & \multicolumn{2}{|l|}{ Model 2} & \multicolumn{2}{|l|}{ Model 3} \\
\hline & Coefficient & SE & Coefficient & SE & Coefficient & SE \\
\hline \multicolumn{7}{|l|}{ Fixed effects } \\
\hline Intercept & -3.81 & 0.37 & -2.08 & 0.35 & -4.32 & 0.45 \\
\hline \multicolumn{7}{|l|}{ Night level } \\
\hline Ashtrays present & $4.97 \dagger$ & 0.46 & & & $5.06 \dagger$ & 0.47 \\
\hline Female & $1.27 \dagger$ & 0.36 & & & $1.09 \dagger$ & 0.45 \\
\hline Male + female & 0.82 & 0.53 & & & -0.41 & 0.94 \\
\hline Employee smoking & $1.95 \dagger$ & 0.45 & & & $2.32 \dagger$ & 0.49 \\
\hline \multicolumn{7}{|l|}{ Bar level } \\
\hline Asian & & & $3.15 \dagger$ & 0.94 & $1.82^{*}$ & 0.95 \\
\hline Irish & & & $4.15 \dagger$ & 1.35 & $2.98^{*}$ & 1.53 \\
\hline Latino & & & 0.09 & 1.13 & 0.46 & 1.20 \\
\hline \multicolumn{7}{|l|}{ Random effects } \\
\hline$\tau_{00}$ & $7.32 \dagger$ & 2.12 & $7.24 \dagger$ & 1.29 & $6.75 \dagger$ & 1.25 \\
\hline
\end{tabular}

observation per bar ("night level"), such as whether formal or informal ashtrays were present, ${ }^{16}$ and (2) characteristics of bars that did not vary from observation to observation ("bar level"). Because a series of four observations took place within each of the randomly selected bars, HLM is an appropriate analytical method, as several observations within each bar should be more similar to one another than to observations about other bars. ${ }^{17}$ Accordingly, we used a random intercept logistic model where only the intercept (that is, log odds of the mean level of compliance) was allowed to vary. We did not find any random patterns in the slopes of the observation level covariates, supporting our modelling approach choice.

Data analyses started with a null model that included only the intercept to estimate the variance in the outcome variable, which was indoor patron smoking (that is, noncompliance with the smoke free workplace law). When the variance of the outcome variable was significant (showing significant variation in the log odds of the mean level of compliance across bars), we then proceeded to the second model, which included only observation level characteristics as the predictors of the outcome variable (table 2), while the intercept was still regarded as random (model 1 , see table 3 ). The next model was composed of only bar level predictors with the random component of the intercept. Finally, we proceeded to the full HLM, which included both observation and bar level predictors so that we could examine how bar level features affect the likelihood of a bar complying with smoking policy, while the model itself corrected for biased standard errors of its coefficients.

\section{FINDINGS}

\section{Bar smoking and ethnicity}

Overall, study 1 observers witnessed at least one person smoking inside, including "border" smoking such as while walking through the bar, or near a doorway or window, in $30 \%$ of the four visits per bar. ${ }^{16}$ Of particular interest for this paper, $9 \%$ of the sampled bars served a preponderance of Asian patrons, $17 \%$ served patrons with a detectable Irish accent, and 7\% served a preponderance of Latino patrons. In roughly a third of the observations, the bartender or bartenders were female only (see table 2 ).

The homogeneity tests of the variance in the intercept from the null model showed that the mean probability of complying with the smoking regulation differed across bars (results not shown). Given this, we proceeded to test the model with the observation level predictors whose results can be found in the second and third columns of table 3 . When the sex of the bartender was female only, patron smoking was more likely to be observed in the bars. According to model 2, Asian and Irish dominated bars are positively related to patron non-compliance, but bars serving primarily Latino patrons are not. Finally, model 3 (incorporating both bar level and observation level variables) shows results in terms of the signs and significance of each variable that are consistent with the previous models.

\section{Female bartenders in ethnically specific bars}

In observations conducted during study $2,82 \%$ of bar staff in bars that primarily served Asian patrons were female, as were $58 \%$ of bar staff in bars serving Irish patrons and $85 \%$ of bar staff in bars serving Latino patrons. That is in comparison with an overall percentage of women constituting $41 \%$ of bartender staff in the randomly selected bars in study 1 .

Observational and interview data supported by survey data suggest that many of the bars catering to Asian and Latino populations strategically employed female staff as an added draw. The provocative dress and pleasant demeanour of women bartenders created a comfortable and intriguing atmosphere for the predominantly male clientele. In some cases female staff members apparently were hired not only as bartenders but also as social coordinators or hostesses, responsible for entertaining patrons.

Latino specific bars in San Francisco appeared to primarily serve the Mexican and Central American men who work as day labourers in and around the San Francisco area. According to our data, most patrons in these bars were men, and most staff persons were women. Frequently the female bar staff were described as wearing revealing and extremely "feminine" clothing, such as low cut blouses and short skirts. One of the project's field observers commented on one of his experiences in a Latino bar:

Both of the [female bartenders] danced a lot, which is also what the female bartenders do at [another] bar. I wonder if they are instructed to dance by the owner in order to attract a male clientele... The presence of attractive, dancing females is noticeable and obvious.

Similarly, patrons in Asian specific San Francisco bars were most often Korean or Cantonese speaking men, and staff persons were mostly women. These workers frequently illustrated the "bar girl" style often found in bars in Asia, where female bar staff socialise and flirt with male patrons and encourage them to spend large amounts of money on drinks and bar food. ${ }^{18}$ Male field observers in these bars 
reported repeated and sometimes aggressive attempts at flirtation from the hostesses; female field observers reported feeling distinctly unwelcome much of the time. In some bars, female staff members appeared to be serving male patrons in private rooms for flirtatious or sexual encounters. A field observer in a Korean bar remarked in his field notes:

All of the private rooms [in the bar] were busy with Asian males. And several Korean male patrons at the counter seemed to be waiting for their turn for private rooms. Mostly Korean young female hostesses [seemed] eager to get their chance in hooking up with the patrons.

Although our field observers were instructed not to investigate any illegal activities such as prostitution in the study bars, there is evidence that such activities do occur at times. For example, during the course of our study, federal agents conducted raids in Asian owned bars throughout the greater San Francisco Bay Area, specifically targeting prostitution as well as gambling and money laundering operations run out of the bars. ${ }^{19}$

Latino and Asian bars in San Francisco appeared to employ immigrant female bartenders to add to the bar's authenticity. These workers spoke the language necessary to communicate with male patrons and were familiar with bar culture in the homeland, providing them with the information necessary to recreate that environment for a predominately immigrant clientele. Similarly, bars serving Irish patrons also appeared to favour immigrant bar staff. With their familiar accents, mannerisms, and shared cultural understandings, bartenders as much as the beer and company drew Irish immigrants to the bars. Unlike the Latino and Asian bars, Irish bartenders and patrons were both men and women, and gender roles did not seem to be as sharply polarised as in bars serving predominantly Asian and Latino patrons.

\section{The smoke free ordinance and female bartenders}

Results show that Latino bars have overwhelmingly complied with the smoke free workforce act, affording women employed by the establishment the benefits of $\mathrm{AB} 13$. Bartenders interviewed spoke of the law in positive terms:

Before, when the California law was that you could, they did smoke, we bartenders inhaled all the smoke. And then you go home and everything stinks of cigarettes. Uhh! But no, not now. Now, thank God they don't smoke inside there [female bartender in SF Latino bar].

Bars catering to primarily Asian patrons were largely noncompliant with $\mathrm{AB} 13$, causing female staff in these bars to be disproportionately deprived of the benefits of this worker protection act. However, Asian female bar staff members interviewed for this study expressed ambivalence toward the smoke free ordinance. This comparatively tolerant attitude may be fostered by cultural norms that accept smoking in bars:

I have never worked for other bars, but I have visited a bunch of bars. A friend of mine owns three bars, and so I have visited them several times. Generally, Americans don't like people to smoke in bars. Smoking is allowed in bars owned by Koreans and the Chinese [female bartender in SF Korean bar].

In San Francisco Irish bars, where we had found low levels of compliance in study 1 , female bartenders nevertheless expressed support for the law:
It makes - it's a lot more healthier for me, as well. Like you can breathe easier, and there's nobody blowin' smoke in your face. Even when you're a smoker and somebody's blowin' smoke in your face, it's just like it's the last thing it's just bad like, $y^{\prime}$ know? [female bartender in SF Irish bar].

Although she did not specifically refer to Ireland's 2004 smoke free bar law, that new policy has successfully changed "pub" life in Ireland, highlighting the positive health consequences of not smoking in bars. ${ }^{20}$ Ireland's recent change in smoking policy does not seem to have affected Irish nationals in California, which may be related to whether they have been exposed first hand to that policy change.

\section{Bar policies and enforcement of the smoke free ordinance}

Interview data showed the ambivalent role of bartenders in implementing the smoke free ordinance. On the one hand, bartenders are the "frontline troops," in that the enforcement of the ordinance on a day to day level within bars is left in the hands of the bartenders. On the other hand, bartenders are bound by the policies set by bar owners, who may or may not wish to comply. According to the law and enforcement structures, city officials such as health inspectors or police officers may cite the bar or individuals for being in violation of the law. In practical terms, police officers and other city officials generally have given this task a low priority. Bars have been cited and fined, and also sued by city attorneys, which is the most costly potential threat. At the time of study 2, Irish bars in particular had been identified as categorically non-compliant, and bars that tobacco control officials considered to be entrenched smokers' havens were targeted in high profile advertising campaigns and lawsuits. Bar owners are aware of the potential costs for being found in violation of $\mathrm{AB}$ 13, and may or may not instruct their staff members to ensure that patrons comply with the law.

It was basically just the owner sayin' no more because we were afraid of getting fines or whatever... Everybody else was kinda getting caught first, so we were like, we're not gonna get caught for something as stupid as a cigarette. It's kinda linked through other bartenders workin' in the Irish bars as well, and they'd let us know what's goin' on. So it's all internetted together like. So it was just "no smoking" signs up, and that was it [bartender in SF Irish bar].

The majority [of people] don't smoke anymore in the bars. Because I think the owners also don't allow it. And they have it there that they can't, that you can't smoke. They've even put up signs that you can't, that smoking is prohibited [female bartender in SF Latino bar].

Although the California state policy is that no one may smoke at a bar at any time, individual bar policies may differ from these to varying degrees. As illustrated above, some

\section{What is already known on this topic}

- Workers of different socioeconomic and demographic backgrounds are exposed to varying degrees of environmental tobacco smoke.

- Smoke free workplace policies reduce employee exposure to environmental tobacco smoke. 
bartenders have reported being instructed to ensure that all patrons comply with the law. In other bars, however, bartenders are either tacitly or overtly instructed to allow some or all patrons to continue to smoke in their bars.

Smokers tend to smoke while drinking. While drinking, they are sitting comfortably and don't want to go outside to smoke. [laughs] Since they feel lazy and want to smoke while drinking, we let them do that [owner, SF Korean bar].

\section{DISCUSSION}

Bars that cater to low SES men often may hire female bartenders to attract this clientele. Flirting is often expected to be part of the job, rewarded with tips. ${ }^{21} 22$ Dancing to or singing along with music from the country of origin is another way that female employees at these bars often entertain their male patrons, as our observers noted. Elaborate sociological descriptions of the gender roles that are acted out on the stage of the bar include Cavan's Liquor License, ${ }^{23}$ Roebuck and Frese's The Rendezvous, ${ }^{24}$ and preeminently, Spradley and Mann's The Cocktail Waitress. ${ }^{21}$ Although Spradley and Mann's description of female cocktail waitresses in weak positions vis-à-vis both male patrons and male managerial staff may read as somewhat dated in the 2 lst century, it bears a noticeable resemblance to the gendered divisions of labour still depicted today in the field observations and interviews in many bars in our study. These gendered roles have direct consequences for female bartenders' abilities to control the environment within which they work, both in terms of social and psychological wellbeing and, (as underscored by studies of employee environmental tobacco smoke exposure), in terms of their physical wellbeing as well.

As the HLM analysis of observations from study l showed, bars serving specific ethnic groups showed dramatically differing rates of compliance. San Francisco bars serving Asian and Irish patrons have been found to be significantly out of compliance with the smoke free law, and Latino bars have been found to be significantly compliant. The impact of this, for female bartenders, is that those working in bars serving Asian and Irish patrons have continued to miss out on the protection from secondhand smoke that California $\mathrm{AB}$ 13-a worker protection act-was intended to provide them.

The role of bar owners is critical in this process. Although many bar owners and bar staff may use an inclusive rhetoric of "we" when discussing bar policies towards smoking, the bottom line is that owners have the final say because they employ bartenders to work in their bars and set the guidelines for their interactions with patrons. Female bartenders in Asian bars, with more rigidly gendered

\section{What this paper adds}

- Within the same jurisdiction subject to smoke free workplace laws, low socioeconomic status women working as bartenders were more likely to be exposed to environmental tobacco smoke than their male counterparts.

- Some of the non-compliance with smoke free bar policy is attributable to gender roles and power relations between female migrant bartenders and their patrons and bar owners.

\section{Policy implications}

Smoke free workplace policies need to be crafted to include enforcement leverage that can create sufficient pressure on bar owners to create smoke free workplaces for their bartending employees, especially women who may not feel empowered to confront their patrons about smoking, given the cultural norms regarding gender relations and indoor smoking in some ethnic groups.

divisions of labour and entrenched smoking norms, are doubly disadvantaged in having little or no say in whether patrons may smoke in the bars in which they work.

It is worth noting, however, that despite the similarly rigidly gendered work environments of the Latina bartenders, they reported (and our observers noted) that they were rarely exposed to environmental tobacco smoke at work. The comparatively strong compliance with smoke free workplace policy in the bars patronised predominantly by Latino patrons may be attributable in part to the bar owners' and staff's respect for the law. In addition to praising her healthier smoke free work environment, one Latina bartender stated, "Well you know that, when you come to this country, the first thing you deal with is hiding from immigration [laughter]. That's why you end up scared, scared whenever you hear about an inspector, police, you get spooked even though you don't owe anything, it's like you say, 'oh, now what? An inspector?"' Thus, the compliance with smoke free bar policy may reflect the desire of both staff and patrons at bars serving Latinos to avoid trouble with law enforcers.

In conclusion, while some female bartenders expressed ambivalence towards smoking in bars, many others described experiencing positive health and social consequences when the bars in which they worked could eliminate interior smoking. The analyses presented here shed light on the benefits of improving the workplace environment for low SES female bartenders through the extension of strong smoke free workplace policies to all workplaces, including bars.

\section{ACKNOWLEDGEMENTS}

We thank Dr Bong Chul Chu for his assistance with conducting the HLM analysis.

\section{Authors' affiliations}

R S Moore, J P Lee, T M J Antin, S E Martin, Prevention Research Center, Pacific Institute for Research and Evaluation, Berkeley, USA

Funding: funding for data collection was provided by California Tobacco-Related Disease Research Program grants 10RT-0276 and 12 RT-0116 and for analysis by National Cancer Institute grant 1R01CA100772-01A, both of which are gratefully acknowledged.

Competing interests: none.

\section{REFERENCES}

1 Kirkby DE. Barmaids: a history of women's work in pubs. Cambridge: Cambridge University Press, 1997.

2 US Census Bureau. Earnings by occupation and education. Washington, DC: US Census Bureau, 2000.

3 Ling PA, Glantz SA. Nicotine addiction, young adults, and smoke-free bars. Drug Alcohol Rev 2002;21:101-4.

4 Nagami DK. Enforcement methods used in applying the California smoke-free workplace act to bars and taverns. Hastings West-Northwest Journal of Environmental Law and Policy 2001;7:159-73.

5 Glantz SA, Balbach, eds. Tobacco war: inside the California battles. Berkeley: University of California Press, 2000.

6 Gilpin EA, Lee L, Pierce JP. Changes in population attitudes about where smoking should not be allowed: California versus the rest of the USA. Tob Control 2004; 13:38-44 
7 Magzamen S, Glantz SA. The new battleground: California's experience with smoke-free bars. Am J Public Health 2001;91:245-52.

8 Eisner MD, Smith AK, Blanc PD. Bartenders' respiratory health after establishment of smoke-free bars and taverns. JAMA 1998;280:1909-14.

9 Biener L, Siegel M. Behavior intentions of the public after bans on smoking in restaurants and bars. Am J Public Health 1997;87:2042-4.

10 Dimich-Ward H, Gee H, Braver M, et al. Analysis of nicotine and cotinine in the hair of hospitality workers exposed to environmental tobacco smoke. J Occup Environ Med 1997;39:946-8.

11 Jarvis $M$, Foulds J, Feyerabend $C$. Exposure to passive smoking among bar staff. Br J Addict 1992;87:111-13.

12 Maskarinec MP, Jenkins RA, Counts RW, et al. Determination of exposure to environmental tobacco smoke in restaurant and tavern workers in one US city. J Expo Anal Environ Epidemiol 2000;10:36-49.

13 Moussa K, Lindstrom M, Ostergren PO. Socioeconomic and demographic differences in exposure to environmental tobacco smoke at work: the Scania Public Health Survey 2000. Scand J Public Health 2004;32:194-202.

14 Shopland DR, Anderson CM, Burns DM, et al. Disparities in smoke-free workplace policies among food service workers. J Occup Environ Med 2004;46:347-56
15 Tang H, Cowling DW, Lloyd JC, et al. Changes of attitudes and patronage behaviors in response to a smoke-free bar law. Am J Public Health 2003;93:611-17.

16 Lee JP, Moore RS, Martin SE. Unobtrusive observations of smoking in urban California bars. J Drug Issues 2003;33:983-1000.

17 Bryk AS, Raudenbush SW. Hierarchical linear models: applications and data analysis methods. Newbury Park: Sage, 1992.

18 Allison A. Nightwork: Sexuality, pleasure, and corporate masculinity in a Tokyo hostess club. Chicago: University of Chicago Press, 1994

19 Lim JH. FBI Busts Korean American sex trafficking ring. Asian Week 2002;23:12.

20 Howell F. Smoke-free bars in Ireland: a runaway success. Tob Control 2005; 14:73-4.

21 Spradley JP, Mann BJ. The cocktail waitress: woman's work in a man's world. New York: Wiley, 1975.

22 Wenzel T. Behind bars: the straight-up tales of a big-city bartender. New York: St Martin's Press, 2003

23 Cavan S. Liquor license: an ethnography of bar behavior. Chicago: Aldine Publishing, 1966.

24 Roebuck JB, Frese W. The rendezvous: a case study of an after-hours club. New York: Free Press, 1976. 